\section{Обоснование номенклатуры запчастей на стадии проектирования}

\author{
В. Н. Шиловский ${ }^{1}$ \\ Петрозаводский государственный университет
}

\section{АННОТАЦИЯ}

В статье рассматривается методический подход и пример обоснования номенклатуры запчастей на стадии проектирования.

Ключевые слова: надежность, номенклатура запасных частей, проектирование лесных машин.

\section{SUMMARU}

This paper contains the methodical way and example of spare parts list ground at the design level.

Keywords: reliability, spare parts list, forest machine design.

Рассмотрим кинематическую и структурные схемы гидроманипулятора лесозаготовительной машины (рис. 1).
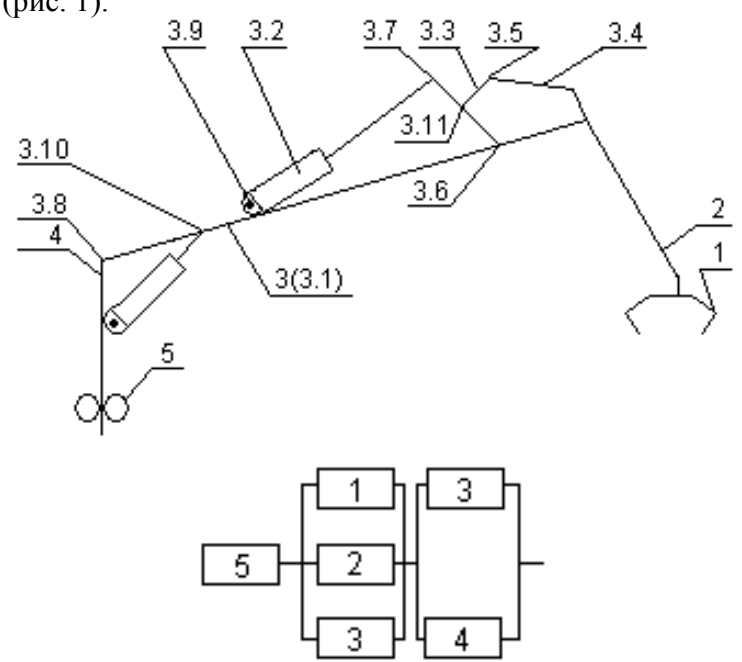

Рис. 1. Кинематическая и структурная схемы гидроманипулятора опытного трелевочного трактора типа ТБ$1 \mathrm{M}-(15,16)$

Согласно методике, изложенной в работе [1], производим расчет показателей надежности и показателей долговечности манипулятора, которые сведены в табл. 1.

Вероятность безотказной работы манипулятора до предельного состояния, согласно структурной схеме надежности, представленной на рис. 1, равна:

\footnotetext{
${ }^{1}$ Автор - профессор кафедры технологии металлов и ремонта

(C) В. Н. Шиловский, 2003
}

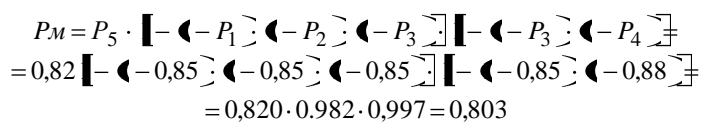

Далее производим построение структурной схемы и расчет показателей надежности стрелы (рис. 2).

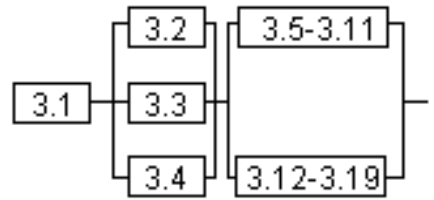

Рис. 2. Структурная схема расчета гамма-процентного ресурса до капитального ремонта стрелы

Выражение вероятности безотказной работы до предельного состояния стрелы имеет вид:

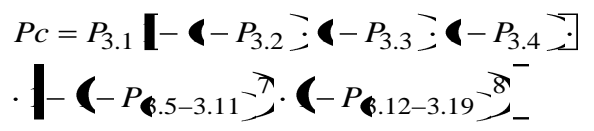

Вероятность отработки стрелой своего ресурса согласно формуле (2) равна:

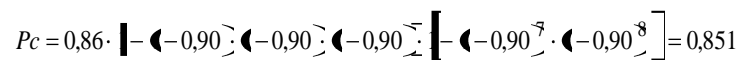

Величина вероятности удовлетворяет требованию, представленному в табл. 1 .

Составим структурную схему и проведем расчет показателей надежности гидроцилиндра стрелы гидроманипулятора (рис. 3,4 ).

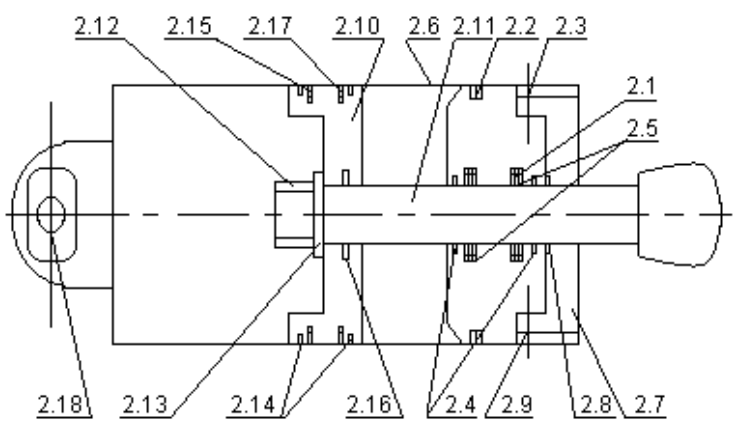

Рис. 3. Детали, составляющие конструкцию гидроцилиндра

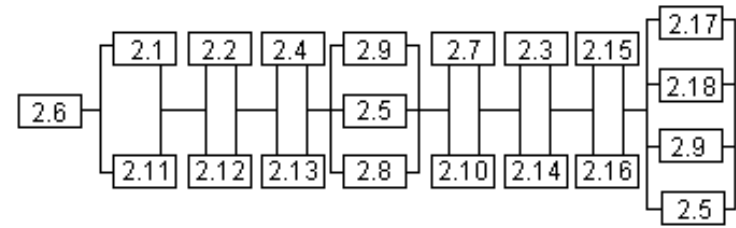

Рис. 4. Структурная схема расчета показателей надежности гидроцилиндра стрелы

Выражение вероятности отработки гидроцилиндром своего ресурса имеет вид: 


$$
\begin{aligned}
& P r=\mathrm{P}_{2.6} \cdot \mathbf{|}-\left(-\mathrm{P}_{2.1}\right)\left(-P_{2.11} \bar{i} \mathbf{|}-\left(-P_{2.2} j\left(-P_{2.12} \bar{i}\right.\right.\right. \\
& \text { |- ( }-P_{2.4} j\left(-P_{2.13}\right) \mathbf{I}-\left(-P_{2.9}\right)\left(-P_{2.6}\right)\left(-P_{2.8}\right) \\
& \text { |- (- } P_{2.7} j\left(-P_{2.10} \bar{j} \mathbf{I}-\left(-P_{2.3} j\left(-P_{2.14} \bar{j}\right.\right.\right. \\
& \text { - |- ( }-P_{2.15} ;\left(-P_{2.16}\right) \mathbf{i}-\left(-P_{2.17} ;\left(-P_{2.18} ;\left(-P_{2.5} \bar{\Sigma}\right.\right.\right.
\end{aligned}
$$

Вероятность отработки гидроцилиндром своего ресурса согласно выражению (3) равна:

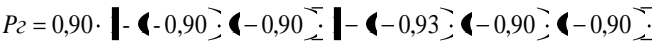

$$
\begin{aligned}
& \text { I- (-0,96; }-0,93 ; \text { I }-0,90 ;(-0,90 ;(-0,96 \text {; } \\
& \text { I- (-0,90; }-0,90 ; \mid \text { I }-0,96 ;-0,90 \text {; } \\
& \mathbf{I}-0,93:(-0,90 \div \mathbf{-}-0,93 ;(-0,90 \div \mathbf{1}-0,93=0,90 \text {. }
\end{aligned}
$$

Результаты расчетов приведены в табл. 1-4.

\section{ОБОСНОВАНИЕ ВКЛЮЧЕНИЯ В НОМЕНКЛАТУРУ ЗАПАСНЫХ ЧАСТЕЙ КОЛЬЦА 115-125-58-2-2}

Установлено, что фактическая надежность кольца характеризуется следующими данными: гаммавосьмидесятипроцентный ресурс $T_{p \gamma}=5000$ моточасам; закон распределения ресурса - Вейбулла; коэффициент вариации ресурса $V=0,6$; отношение среднего к гамма-восьмидесятипроцентному ресурсу $K_{\gamma}=2,0$; вероятность безотказной работы до предельного состояния $P_{k}=0,80$.

Рассмотрим варианты холодного резервирования кольца, с целью повышения вероятности безотказной его работы, до требуемой величины, равной 0,93 .

\section{Вариант I}

Включение кольца в групповой комплект запчастей на пять тракторов

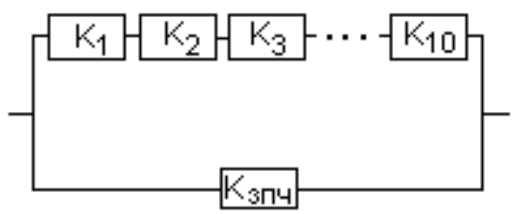

$$
\begin{aligned}
& P_{k}=1-\left(-P_{k 33 \Pi} \dot{\zeta}-P_{k 1} \cdot P_{k 2} \cdot P_{k 3} \cdot \ldots \cdot P_{k 10}\right) \\
& =1-(-0,80)\left(-0,80^{10} \frac{\bar{\gamma}}{\bar{\gamma}} 0,816\right.
\end{aligned}
$$

\section{Вариант II}

Включение кольца в комплект на два трактора

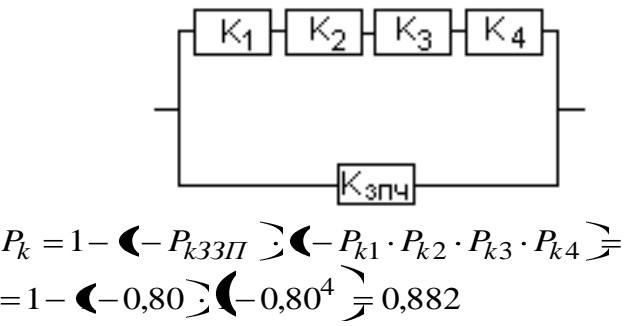

\section{Вариант III}

Включение кольца в индивидуальный комплект запасных частей

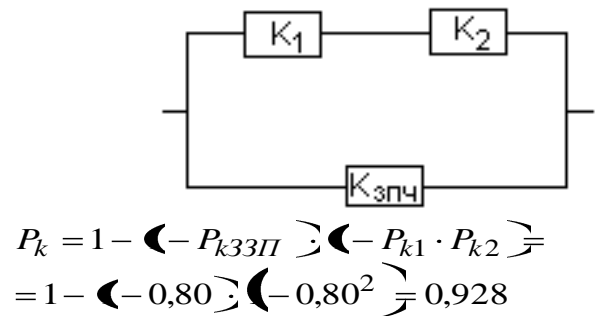

Вывод: Необходимо включение одного кольца в индивидуальный комплект ЗПЧ.

\section{СПИСОК ЛИТЕРАТУРЫ}

1. Надежность машин: Методические указания по расчету надежности на стадии проектирования машин и оборудования / А. В. Питухин, В. Н. Шиловский. Петрозаводск: Изд-во ПетрГУ, 1994. $40 \mathrm{c}$.

Итоговые расчеты показателей надежности узлов манипулятора

Таблица 1

\begin{tabular}{|l|c|c|c|c|c|c|c|c|c|c|c|}
\hline Наименование узла & $\begin{array}{c}T_{p}, \\
\text { мото-ч. }\end{array}$ & $K_{i}$ & $\begin{array}{c}T_{p i}^{\prime}, \\
\text { мото-ч. }\end{array}$ & $\begin{array}{l}\text { Шифр* } \\
\text { Закон распре- }\end{array}$ & $\begin{array}{l}V_{i} \\
\text { деления ** }\end{array}$ & $\begin{array}{c}T_{p j i}, \\
\text { мото-ч. }\end{array}$ & $\begin{array}{c}T_{p j i}^{\prime}, \\
\text { мото-ч. }\end{array}$ & $K_{\gamma i}$ & $P_{i}$ & $\begin{array}{c}\text { Время } \\
\text { замены, } \\
\text { отн.ед. }\end{array}$ \\
\hline 1. Захватное устройство & 10000 & 1 & 10000 & 2222 & В & 0,50 & 5000 & 5000 & 2,0 & 0,85 & $0,25 * * *$ \\
\hline 2. Рукоять & 10000 & 1 & 10000 & 2222 & В & 0,50 & 5000 & 5000 & 2,0 & 0,85 & 0,35 \\
\hline 3. Стрела & 10000 & 1 & 10000 & 2222 & В & 0,50 & 5000 & 5000 & 2,0 & 0,85 & 0,50 \\
\hline 4. Колонна & 10000 & 1 & 10000 & 2212 & В & 0,46 & 5000 & 5000 & 2,0 & 0,88 & 0,60 \\
\hline 5. Основание & 10000 & 1 & 10000 & 2212 & В & 0,50 & 5000 & 5000 & 2,0 & 0,82 & 1,00 \\
\hline
\end{tabular}

Примечание: * шифр факторов, определяющих закон распределения ресурса, установлен согласно работе [1]; ** В - Вейбулла; *** время в долях времени разборки-сборки всего узла.

$T_{p}$ - средний ресурс, $K_{i}$ - коэффициент загрузки узла, $T_{p i}^{\prime}, T_{p}^{\prime} i-$ соответственно средний и гаммавосьмидесятипроцентный ресурс узла в единицах собственной наработки, $V_{i}$ - коэффициент вариации ресурса, 
$K_{y i}$ - соотношение среднего и гамма-восьмидесятипроцентного ресурса, $P_{i}$ - вероятность отработать гаммапроцентный ресурс.

Таблица 2

Итоговые расчеты показателей надежности узлов стрелы

\begin{tabular}{|c|c|c|c|c|c|c|c|c|c|c|c|}
\hline Наименование узла & $T_{p}$, мото-ч. & $K_{i}$ & $\begin{array}{c}T_{p i}^{\prime} \\
\text { мото-ч. }\end{array}$ & Шифр & $\begin{array}{c}\text { Закон } \\
\text { распре- } \\
\text { деления }\end{array}$ & $V_{i}$ & $\begin{array}{c}T_{p \gamma i}, \\
\text { мото-ч. }\end{array}$ & $\begin{array}{c}T_{p \gamma i}^{\prime} \\
\text { мото-ч. }\end{array}$ & $K_{\gamma i}$ & $P_{i}$ & $\begin{array}{c}\text { Время } \\
\text { замены, } \\
\text { отн. ед. }\end{array}$ \\
\hline 3.1. Корпус стрелы & 10000 & 1,0 & 10000 & 2222 & B & 0,45 & 5000 & 5000 & 2,0 & 0,86 & 1,0 \\
\hline 3.2. Гидроцилиндр & 10000 & 1,0 & 10000 & 2222 & B & 0,40 & 5000 & 5000 & 2,0 & 0,90 & 0,45 \\
\hline 3.3. Рычаг & 10000 & 1,0 & 10000 & 2222 & $\mathrm{~B}$ & 0,40 & 5000 & 5000 & 2,0 & 0,90 & 0,50 \\
\hline 3.4. Тяга & 10000 & 1,0 & 10000 & 2222 & B & 0,40 & 5000 & 5000 & 2,0 & 0,90 & 0,35 \\
\hline 3.5. Палец & 10000 & 1,0 & 10000 & 2222 & B & 0,40 & 5000 & 5000 & 2,0 & 0,90 & 0,10 \\
\hline 3.6. Палец (2 шт.) & 10000 & 1,0 & 10000 & 2222 & B & 0,40 & 5000 & 5000 & 2,0 & 0,90 & 0,10 \\
\hline 3.7. Палец & 10000 & 1,0 & 10000 & 2222 & B & 0,40 & 5000 & 5000 & 2,0 & 0,90 & 0,10 \\
\hline 3.8. Палец & 10000 & 1,0 & 10000 & 2222 & B & 0,40 & 5000 & 5000 & 2,0 & 0,90 & 0,10 \\
\hline 3.9. Палец & 10000 & 1,0 & 10000 & 2222 & B & 0,40 & 5000 & 5000 & 2,0 & 0,90 & 0,10 \\
\hline 3.10. Палец & 10000 & 1,0 & 10000 & 2222 & B & 0,40 & 5000 & 5000 & 2,0 & 0,90 & 0,10 \\
\hline 3.11. Палец & 10000 & 1,0 & 10000 & 2222 & B & 0,40 & 5000 & 5000 & 2,0 & 0,90 & 0,10 \\
\hline $\begin{array}{l}\text { 3.12. Рукав высоко- } \\
\text { го давления (РВД) }\end{array}$ & 10000 & 1,0 & 10000 & 2222 & B & 0,40 & 5000 & 5000 & 2,0 & 0,90 & 0,10 \\
\hline 3.13. РВД & 10000 & 1,0 & 10000 & 2222 & B & 0,40 & 5000 & 5000 & 2,0 & 0,90 & 0,05 \\
\hline 3.14. РВД & 10000 & 1,0 & 10000 & 2222 & $\mathrm{~B}$ & 0,40 & 5000 & 5000 & 2,0 & 0,90 & 0,05 \\
\hline 3.15. РВД & 10000 & 1,0 & 10000 & 2222 & B & 0,40 & 5000 & 5000 & 2,0 & 0,90 & 0,05 \\
\hline 3.16. РВД & 10000 & 1,0 & 10000 & 2222 & B & 0,40 & 5000 & 5000 & 2,0 & 0,90 & 0,05 \\
\hline 3.17. РВД & 10000 & 1,0 & 10000 & 2222 & B & 0,40 & 5000 & 5000 & 2,0 & 0,90 & 0,05 \\
\hline 3.18. РВД & 10000 & 1,0 & 10000 & 2222 & B & 0,40 & 5000 & 5000 & 2,0 & 0,90 & 0,05 \\
\hline 3.19. РВД & 10000 & 1,0 & 10000 & 2222 & B & 0,40 & 5000 & 5000 & 2,0 & 0,90 & 0,05 \\
\hline
\end{tabular}

Примечание: $T_{p}$ - средний ресурс, $K_{i}$ - коэффициент загрузки узла, $T_{p i}^{\prime}, T_{p}^{\prime}{ }_{i}-$ соответственно средний и гамма-восьмидесятипроцентный ресурс узла в единицах собственной наработки, $V_{i}$ - коэффициент вариации ресурса, $K_{\gamma i}$ - соотношение среднего и гамма-восьмидесятипроцентного ресурса, $P_{i}$ - вероятность отработать гаммапроцентный ресурс.

Таблица 3

Относительное время замен и режим работы деталей гидроцилиндра

\begin{tabular}{|l|c|c|c|c|}
\hline \multicolumn{1}{|c|}{ Наименование детали } & Номер по каталогу & Шифр & Время замены, отн.ед. & $\begin{array}{c}\text { Коэффициент } \\
\text { использования }\end{array}$ \\
\hline \multicolumn{1}{|c|}{1} & 2 & 3 & 4 & 5 \\
\hline 2.1. Кольцо уплотнительное & МБ-110.05.612 & 1221 & 0,70 & 1,0 \\
\hline 2.2. Кольцо уплотнительное & $115-125-58-2-2$ & 1121 & 0,70 & 1,0 \\
\hline 2.3. Втулка & МУ-80.36.00 & 1121 & 0,65 & 1,0 \\
\hline 2.4. Втулка & МУ-80.36.008 & 1121 & 0,70 & 1,0 \\
\hline 2.5. Кольцо защитное & МУ-80.36.009 & 2121 & 0,10 & 1,0 \\
\hline 2.6. Гильза цилиндра & МУ-80.36.110. & 1221 & 1,00 & 1,0 \\
\hline 2.7. Гайка (крышка) & МУ-80.36.003 & 1221 & 0,75 & 1,0 \\
\hline 2.8. Грязесъемник & $3-63$ & 1121 & 0,80 & 1,0 \\
\hline 2.9. Винт В.М8-6д* $12.14 \mathrm{H}$ & & 1221 & 0,10 & \\
\hline
\end{tabular}




\begin{tabular}{|l|c|c|c|c|}
\multicolumn{1}{|c|}{ Продолжение табл. 3} \\
\hline \multicolumn{1}{|c|}{1} & 2 & 3 & 4 & 5 \\
\hline 2.10. Поршень & МУ-80.36.001 & 1221 & 0,50 & 1.0 \\
\hline 2.11. Шток & МУ-80.36.330 & 2221 & 0,55 & 1.0 \\
\hline 2.12. Гайка & МУ-80.36.006 & 1221 & 0,45 & 1.0 \\
\hline 2.13. Шайба & МУ-80.36.007 & 2121 & 0,50 & 1.0 \\
\hline 2.14. Втулка & МУ-80.36.004 & 1221 & 0,60 & 1.0 \\
\hline 2.15. Кольцо уплотнительное & МУ-80.36.005 & 1121 & 0,60 & 1.0 \\
\hline 2.16. Кольцо уплотнительное & $050-058-46-2-2$ & 1221 & 0,60 & 1.0 \\
\hline 2.17. Кольцо уплотнительное & $115-125-58-22$ & 1121 & 0,60 & 1.0 \\
\hline 2.18. Подшипник ШС-50 & 100 Б-2621106 & 1221 & 0,20 & \\
\hline
\end{tabular}

Таблица 4

Итоговые расчеты показателей долговечности деталей гидроцилиндра привода стрелы

\begin{tabular}{|l|c|c|c|c|c|c|c|c|}
\hline \multicolumn{1}{|c|}{ Наименование и номер по каталогу } & $\begin{array}{c}T_{p}, \\
\text { мото-ч. }\end{array}$ & $\begin{array}{c}T_{p j}, \\
\text { мото-ч. }\end{array}$ & $\begin{array}{c}\text { Закон } \\
\text { распеде- } \\
\text { ления }\end{array}$ & $V_{i}$ & $\begin{array}{c}T_{p \gamma}, \\
\text { мото-ч. }\end{array}$ & $\begin{array}{c}T_{p}^{\prime} \\
\text { мото-ч. }\end{array}$ & $K_{\gamma}$ & $P_{i}$ \\
\hline 2.1. Кольцо уплотнительное МБ-110.05.612 & 10000 & 10000 & В & 0,40 & 5000 & 5000 & 2,0 & 0,90 \\
\hline 2.2. Кольцо уплотнительное 115-125-58-2-2 & 10000 & 10000 & н $^{*}$ & 0,35 & 7500 & 7500 & 1,5 & 0,93 \\
\hline 2.3. Втулка МУ-80.36.00 & 10000 & 10000 & н & 0,30 & 7500 & 7500 & 1,5 & 0,96 \\
\hline 2.4. Втулка МУ-80.36.008 & 10000 & 10000 & н & 0,30 & 7500 & 7500 & 1,5 & 0,96 \\
\hline 2.5. Кольцо защитное МУ-80.36.009 & 10000 & 10000 & н & 0,35 & 7500 & 7500 & 1,5 & 0,93 \\
\hline 2.6. Гильза цилиндра МУ-80.36.110 & 10000 & 10000 & В & 0,40 & 5000 & 5000 & 2,0 & 0,90 \\
\hline 2.7. Гайка (крышка) МУ-80.36.003 & 10000 & 10000 & В & 0,40 & 5000 & 5000 & 2,0 & 0,90 \\
\hline 2.8. Грязесьемник 3-63 & 10000 & 10000 & н & 0,30 & 7500 & 7500 & 1,5 & 0,96 \\
\hline 2.9. Винт В.М8-6д* 12.14Н & 10000 & 10000 & В & 0,40 & 5000 & 5000 & 2,0 & 0,90 \\
\hline 2.10. Поршень МУ-80.36.001 & 10000 & 10000 & В & 0,40 & 5000 & 5000 & 2,0 & 0,90 \\
\hline 2.11. Шток МУ-80.36.330 & 10000 & 10000 & В & 0,40 & 5000 & 5000 & 2,0 & 0,90 \\
\hline 2.12. Гайка МУ-80.36.006 & 10000 & 10000 & В & 0,40 & 5000 & 5000 & 2,0 & 0,90 \\
\hline 2.13. Шайба МУ-80.36.007 & 10000 & 10000 & н & 0,35 & 7500 & 7500 & 1,5 & 0,93 \\
\hline 2.14. Втулка МУ-80.36.004 & 10000 & 10000 & В & 0,40 & 5000 & 5000 & 2,0 & 0,90 \\
\hline $\begin{array}{l}\text { 2.15. Кольцо уплотнительное } \\
\text { МУ-80.36.005 }\end{array}$ & 10000 & 10000 & н & 0,35 & 7500 & 7500 & 1,5 & 0,93 \\
\hline 2.16. Кольцоуплотнительное 050-058-46-2-2 & 10000 & 10000 & В & 0,40 & 5000 & 5000 & 2,0 & 0,90 \\
\hline 2.17. Кольцо уплотнительное 115-125-58-2-2 & 10000 & 10000 & н & 0,35 & 7500 & 7500 & 1,5 & 0,93 \\
\hline 2.18. Подшипник ШС-50 & 10000 & 10000 & В & 0,40 & 5000 & 5000 & 2,0 & 0,90 \\
\hline
\end{tabular}

Примечание: *н - нормальный.

$T_{p}$ - средний ресурс, $K_{i}$ - коэффициент загрузки узла, $T_{p i}^{\prime}, T_{p}^{\prime}$ - соответственно средний и гаммавосьмидесятипроцентный ресурс узла в единицах собственной наработки, $V_{i}$ - коэффициент вариации ресурса, $K_{\gamma i}$ - соотношение среднего и гамма-восьмидесятипроцентного ресурса, $P_{i}$ - вероятность отработать гаммапроцентный ресурс.

$T_{p}$ - средний ресурс, $K_{i}$ - коэффициент загрузки узла, $T_{p i}^{\prime}, T_{p}^{\prime} i-$ соответственно средний и гаммавосьмидесятипроцентный ресурс узла в единицах собственной наработки, $V_{i}$ - коэффициент вариации ресурса, $K_{j i}$ - соотношение среднего и гамма-восьмидесятипроцентного ресурса, $P_{i}$ - вероятность отработать гаммапроцентный ресурс. 